\title{
MÉTODOS LABORATORIAIS PARA O DIAGNÓSTICO DA INFECÇÃO PELO VÍRUS DA IMUNODEFICIÊNCIA HUMANA (HIV)
}

\author{
LABORATORY METHODS FOR THE DIAGNOSIS OF HUMAN \\ IMMUNODEFICIENCY VIRUS (HIV) INFECTION
}

Alcyone A. Machado ${ }^{1}$ \& João Carlos da Costa ${ }^{2}$

\begin{abstract}
1Docente da Divisão de Moléstias Infecciosas e Parasitárias 2Professor Colaborador - Departamento de Clínica Médica da Faculdade de Medicina de Ribeirão Preto da Universidade de São Paulo

Correspondência: Profa.Dra. Alcyone Artioli Machado. Departamento de Clínica Médica da Faculdade de Medicina de Ribeirão Preto da Universidade de São Paulo. Avenida Bandeirantes, 3900 - CEP: 14048-900 - Ribeirão Preto - São Paulo, Brasil; Fax: 55-16-633.1144 ou 633.6695. E-mail: aamachad@fmrp.usp.br
\end{abstract}

MACHADO AA \& COSTA JC. Métodos laboratoriais para o diagnóstico da infecção pelo vírus da imunodeficiência humana (HIV). Medicina, Ribeirão Preto, 32: 138-146, abr./jun. 1999.

RESUMO: Os autores revisam os principais métodos laboratoriais, atualmente conhecidos e disponíveis para o diagnóstico da infecção pelo Vírus da Imunodeficiência Humana (HIV), salientando as orientações gerais sobre sua aplicação e interpretação.

UNITERMOS: HIV. Síndrome de Imunodeficiência Adquirida. Diagnóstico Laboratorial. ELISA. Western Blotting.

Desde os relatos dos primeiros casos da Síndrome de Imunodeficiência Adquirida (aids), no início da década de $1980^{(1,2)}$, até o isolamento e identificação do Vírus da Imunodeficiência Humana, tipo 1 (HIV-1), como agente causador da síndrome, em 1983-1984(3,4), os pesquisadores vêm buscando métodos laboratoriais capazes de auxiliar no diagnóstico da afecção.

Finalmente, em 1985, os testes dos doadores de sangue passam a ser disponíveis, rotineiramente, através do primeiro "kit" de ensaio imunoenzimático (ELISA), que estabeleu HIV-1 ELISA como a primeira ferramenta de triagem diagnóstica ${ }^{(5,6)}$. A sua implantação ocorreu, primeiramente, nos bancos de sangue e, posteriormente, como método diagnóstico para os indivíduos de risco para a infecção pelo HIV-1.

Os testes laboratoriais caminham lado a lado com o rápido conhecimento da fisiopatogenia da aids e do complexo ciclo replicativo do HIV-1 ${ }^{(7,8,9)}$.
Existem dois retrovírus capazes de levar à Síndrome de Imunodeficiência Adquirida, o HIV-1 e o HIV-2. Este último tem sido descrito em diferentes regiões do mundo, mas, sempre, em indivíduos que tiveram algum contato com o Continente Africano ou sua população ${ }^{(10,11)}$. Em termos laboratoriais, os métodos são específicos para um ou outro vírus, e devem ser tomados certos cuidados em determinadas interpretações devido a erros que possam ocorrer com os diferentes métodos laboratoriais, quando da pesquisa dos dois vírus ${ }^{(12)}$.

\section{TESTE PARA DETECÇÃO DO HIV}

O método laboratorial mais direto para detectar HIV-1, em pacientes, é a cultura do vírus através do cocultivo de células mononucleares do sangue periférico, plasma ou células ganglionares, com estimulação de Peripheral Blood Mononuclear Cells-PBMCs de doadores não infectados ${ }^{(13)}$. Em condições apro- 
priadas, em um sistema de cultura in vitro, faz-se uma explosiva infecção viral, conduzindo à produção de milhões de virions. A cultura é lida como positiva pela formação de sincícios (isto é, células gigantes, multinucleares, resultantes da fusão célula-célula), detecção da atividade da transcriptase reversa ou presença do antígeno p24 no sobrenadante da cultura, eventos estes que traduzem replicação viral.

Este método tem um alto custo, pressupõem uma equipe de técnicos treinados e condições laboratoriais de isolamento e segurança (confinamento PII ou PIII). É demorado, obtendo-se resultados após quinze (15) a trinta (30) dias, ou mais, de cultivo. Por isso, sua indicação, atualmente, vem se restringindo à área de pesquisa clínica. Essa técnica apresenta defeitos de reprodutibilidade ligados à variabilidade das células mononucleares dos doadores. A seleção de cepas de replicação rápida, in vitro, pode provocar um viés de medição. Devido a todos esses fatores, outros métodos têm sido desenvolvidos para detecção da infecção pelo HIV, com o intuito de diagnóstico. Muitas dessas técnicas baseiam-se na detecção da resposta de anticorpos contra o HIV, mais do que na detecção do próprio vírus ${ }^{(14,15)}$.

\section{TESTES DE DETECÇÃO DE ANTICORPOS}

As técnicas mais frequientemente utilizadas para pesquisa de anticorpos anti-HIV são: teste imunoenzimático (Enzyme Linked Immunosorbent Assay-ELISA), fluorimetria, quimioluminescência, radioimunoprecipitação (Radio Immunoprecitation Assay-RIPA), aglutinação de partículas de látex, imunofluorescência indireta (If) e Western-Blot (WB).

O ELISA e o WB têm, atualmente, alta sensibilidade $(99 \%)^{(14,16)}$.

Em termos de diagnóstico sorológico de infecção pelo HIV, o Ministério da Saúde do Brasil preconiza que seja realizado o ELISA, em duplicata, como método de triagem, e um outro método como teste confirmatório de positividade, que pode ser a aglutinação de partículas de látex, ou a If, na dependência das condições do laboratório. Ao realizar-se o ELISA:

1 - caso o exame seja negativo, considera-se negativa a amostra;

2 - se o resultado for duvidoso ou indeterminado, deve-se repetir o procedimento em duplicata, e, persistindo a dúvida, proceder ao teste confirmatório (If ou aglutinação do látex);

3 - se a amostra for positiva, realizar o teste confirmatório.
Realizando-se o teste confirmatório (If ou aglutinação do látex):

a) se positivo, repetir, em nova amostra, todo o procedimento;

b) se indeterminado ou negativo, realizar WB.

Em bancos de sangue, realiza-se, como método confirmatório, o WB em todas as amostras.

Como principal limitação da pesquisa de anticorpos para o HIV, temos que lembrar que, em $75 \%$ dos casos, os anticorpos tornam-se detectáveis cerca de dois (2) a três (3) meses após o contato com o vírus; assim, nos pacientes em que haja forte suspeita da infecção pelo HIV, e a pesquisa de anticorpos resulte negativa, haverá necessidade da repetição do teste após um ou dois meses do possível contágio. Em alguns casos, esses testes, em especial o ELISA, podem tornar-se positivos somente após seis (6) meses do contágio; assim, o seguimento clínico é fundamental.

Uma vez positivo, o resultado não se negativa até o final da vida. Em raríssimos casos, em condições de imunodeficiência celular e humoral extrema, nas fases finais da doença, pode ocorrer negativação dos anticorpos pelo ELISA.

\section{INTERPRETAÇÃO DO RESULTADO PELO ELISA E CONFIRMATÓRIO}

Adulto reagente: indica contato anterior com o HIV.

Recém-nascido reagente: o encontro de anticorpos IgG (ELISA, WB), no sangue para o vírus, não permite o diagnóstico da infecção antes dos quinze a dezoito (15-18) meses de idade, devido à possibilidade de transferência passiva de anticorpos da mãe para o feto, havendo, assim, necessidade de métodos laboratoriais de detecção direta do vírus ou de seus antígenos. Deve-se lembrar que, no Brasil, cerca de $90 \%$ dos casos de aids na infância deve-se à transmissão mãe-filho do HIV.

Adulto não reagente: indica que o indivíduo não entrou em contato com o HIV-1 ou, caso tenha havido infecção, ainda não soroconverteu, porém poderá fazê-lo em algumas semanas.

ELISA indeterminado: pode se tratar de indivíduo em fase de soroconversão, em vias de se tornar reagente, ou pacientes em fase terminal da doença, ou se tratar da detecção de anticorpos inespecíficos que se ligam casualmente, sem significado clínico, como reação cruzada, como aloanticorpos, pacientes 
com doenças auto-imunes; pode ocorrer, também, quando há infecção pelo HIV-2 e nos casos de participantes de ensaios em vacinas anti-HIV. Nessas circunstâncias, sugere-se a repetição do teste em uma nova amostra, e, caso persistam dúvidas, faz-se o seguimento sorológico do paciente e após trinta (30) a sessenta (60) dias, repetindo-se o teste anteriormente solicitado para nova avaliação. Quando o teste WB também resultar indeterminado, sugere-se novo WB após trinta (30) dias ou a reação de cadeia de polimerase (PCR).

\section{INTERPRETAÇÃO DO TESTE DE WES- TERN-BLOT $(\mathbf{W B})^{(17)}$}

O teste WB tem o mesmo princípio do ELISA, isto é, captura de anticorpos, porém com antígenos específicos do HIV, previamente separados eletroforeticamente ${ }^{(16,18)}$. Na técnica de WB, existe a possibilidade de se revelar a presença de anticorpos contra nove (9) proteínas do HIV-1: gp160, gp120, gp42, p66, p51, p31, p55, p24, p17. As três primeiras são codificadas pelo gene env, as três seguintes, pelo gene pol e as restantes, pelo gene gag. Soros que apresentem reatividade contra pelo menos uma proteína de cada um dos três grupos gênicos são considerados reagentes. Soros que apresentem reatividade contra, pelo menos, uma proteína de dois grupos gênicos diferentes, sendo uma delas obrigatoriamente do env, são considerados reagentes. Soros que apresentem reatividade contra duas proteínas do env são igualmente considerados reagentes. Soros que apresentem reatividade contra, pelo menos, uma proteína de dois grupos gênicos diferentes, desde que não sejam do $e n v$, são considerados indeterminados. Soros que apresentem reatividade contra, pelo menos, uma proteína de um grupo gênico, desde que não seja p17, são considerados indeterminados. Soros que reajam isoladamente contra p17 são considerados negativos. Soros que não reajam contra nenhuma proteína são, obviamente, considerados negativos.

A Figura 1 ilustra exemplo de teste WB.
O modelo de bandas específicas pode variar de indivíduo para indivíduo, e a intensidade pode flutuar de acordo com a relativa quantidade de anticorpo antiHIV-1 específico, circulante em algum dado momento e com a preparação comercial em uso. Muitas preparações de WB comerciais são especificamente sensíveis para a detecção de anticorpo anti-p24 e o seu aparecimento no "imunoblotting" pode ocorrer relativamente cedo no período pós-exposição ao vírus, ocasionalmente servindo para anunciar o processo de soroconversão. O aparecimento de níveis detectáveis de anticorpos contra os produtos dos genes pol e env pode ser mais tardio, embora isso seja, usualmente, tão breve que seu impacto no sorodiagnóstico é muito pequeno. Anticorpos contra outros genes do HIV-1, tais como nef ou outros elementos reguladores, são, geralmente, não detectáveis pelo WB convencional. É importante ter em mente que o WB não é indicado como um teste de triagem inicial. Devido à alta freqüência de reações indeterminadas, a maioria das quais pode ser não específica, o WB não é apropriado como ferramenta para uso em triagem inicial de grandes populações. Seu emprego deve ser reservado como um teste confirmatório, em especial em populações em que tenha havido positividade pelo ELISA ou outro teste em uma triagem inicial ${ }^{(14)}$.

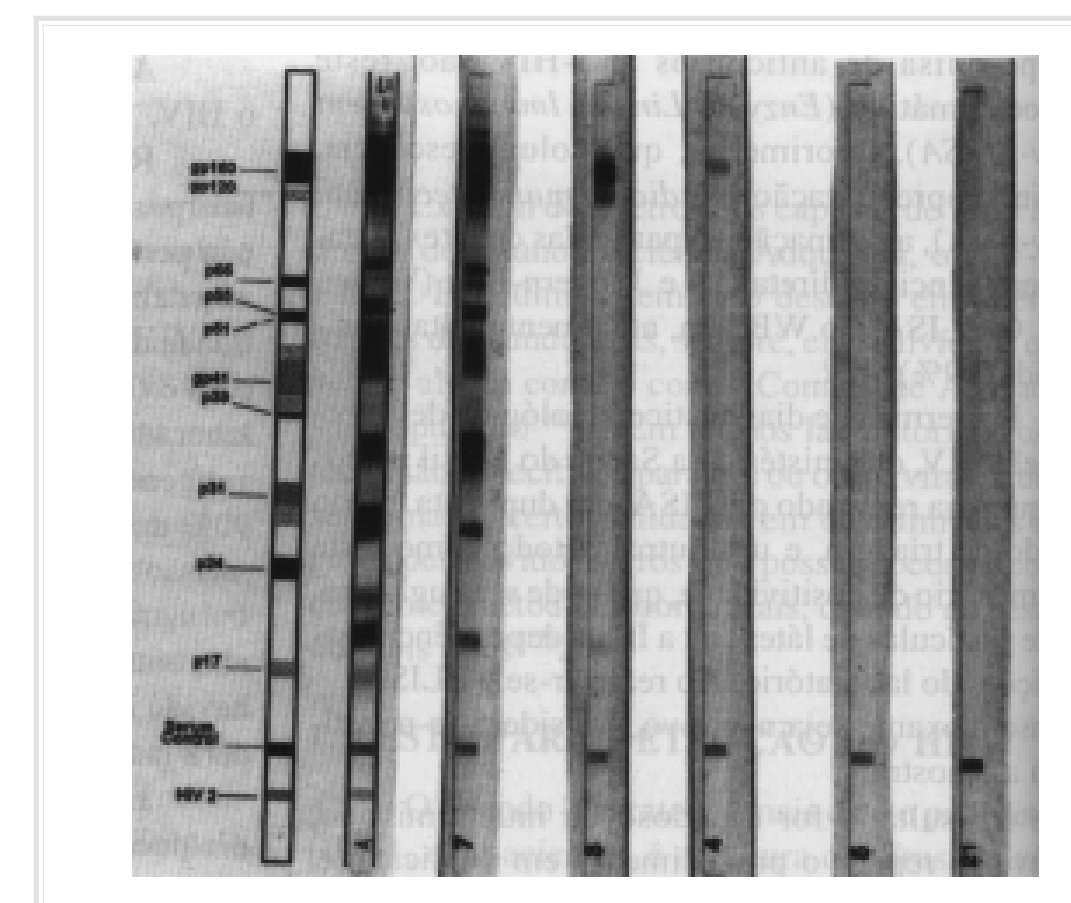

Figura 1 - Western Blot. Representativos Western Blot para HIV-1. Segundo os critérios de interpretação (vide texto), os soros $A E 7$ são considerados positivos, soros 3 e 4 indeterminados e os soros de números 5 e 21 negativos. 


\section{IMUNOFLUORESCÊNCIA INDIRETA $(\text { IF })^{(14)}$}

Apesar da rapidez e facilidade do emprego do WB como teste confirmatório, alguns laboratórios têm preferido usar a imunofluorescência indireta (If) como um teste confirmatório ou mesmo em triagem. A vantagem desse método é que ele é rápido e muito fácil de ser realizado, requerendo todavia habilidade na leitura, que é subjetiva. Entretanto, requer a existência, no laboratório, de microscópio de fluorescência, o que encarece o método, assim como é necessário confiar-se no fornecedor das lâminas, as quais devem conter células infectadas pelo HIV-1 (geralmente, linhagens $\mathrm{H} 9$ ou CEM). A If pode tornar-se positiva mais cedo, no transcurso da infecção pelo HIV-1, do que a do ELISA ou a do WB.

\section{RADIOIMUNOPRECIPITAÇÃO (RIPA) ${ }^{(14)}$}

RIPA é um outro teste que pode, eventualmente, ser utilizado como teste confirmatório, embora restrito aos laboratórios que mantenham continuamente culturas celulares para o HIV-1.

Vários aspectos deste método inviabilizam a sua adoção em laboratórios clínicos e o torna menos atraente que o WB para uso na rotina: a necessidade de manter estoque de vírus e linhagens celulares para cultura, a necessidade de estocagem e manutenção de material radioativo, além de cuidados especiais com os resíduos e experiência do pessoal técnico. Entretanto há certas circunstâncias em que o clínico pode, eventualmente, lançar mão do RIPA, em especial na detecção de baixos títulos de anticorpos ou na avaliação de indivíduos com padrões indeterminados de WB.

A sensibilidade e especificidade do RIPA, usualmente, excedem aquelas do WB e o RIPA tem proporcionado esclarecimentos em relação à natureza da resposta sorológica para proteínas de alto peso molecular do envelope viral (gp120, gp160), em estádios precoces no processo de soroconversão. Entretanto, nos estádios iniciais da infecção, o RIPA pode ser menos sensível que o WB, na detecção de anticorpo para antígenos virais p24 ou gp41.

\section{TESTE RÁPIDO DE AGLUTINAÇÃO DO LÁTEX ${ }^{(14)}$}

A complexidade e o custo dos diversos testes para detecção de anticorpos anti-HIV-1 têm estimulado o desenvolvimento de testes de mais fácil reali- zação, com baixo custo. Entre estes métodos está o teste rápido de aglutinação do látex, um processo que pode ser realizado em minutos e que requer o mínimo de reagentes e habilidade técnica. Este método é uma modificação do teste padrão de aglutinação de látex e usa proteínas recombinantes, derivadas de região altamente conservada do genoma do HIV-1, ligadas a esferas de polistireno.

Alguns trabalhos têm estimado sua sensibilidade em $99,3 \%$ e especificidade em $100 \%$, em comparação ao WB. Entretanto, a interpretação destes resultados deve ser feita com cautela, uma vez que foram aplicados em populações com incidência de infecção acima de $18 \%{ }^{(14)}$.

\section{TESTE DE DETECÇÃO DE ANTÍGENO P24 ${ }^{(14)}$}

A técnica mais empregada para a pesquisa de antígeno p24 é o teste de ELISA. A indicação é no diagnóstico laboratorial precoce de infecções pelo HIV-1, na fase anterior à conversão sorológica e no diagnóstico da infecção pelo HIV-1 no recém-nascido de mãe soropositiva. Até pouco tempo atrás, antes da existência da quantificação da carga viral do HIV-1 de maneira rotineira, ele era usado na avaliação da necessidade de introdução e monitorização da terapêutica anti-retroviral. Uma limitação para seu uso é que $40 \%$ a $70 \%$ dos pacientes, na fase aguda, têm viremia detectada por este critério. Após esta fase inicial de cerca de dois (2) a três (3) meses, este marcador permanece, habitualmente, indetectável, ou detectável, esporadicamente. Uma outra limitação é que ele somente é capaz de detectar antígeno p24 livre e não os antígenos complexados com anticorpos anti-p24.

$\mathrm{O}$ encontro do teste reagente indica a presença de antígeno do HIV-1 ou p24 circulante em níveis superiores a $8 \mathrm{pg} / \mathrm{ml}$ (limite médio de sensibilidade do teste). No caso de recém-nascidos, indica infecção. A leitura não reagente indica ausência de antígeno detectável, dentro dos limites de sensibilidade da técnica.

\section{TESTES DE AMPLIAÇÃO DO GENOMA DO HIV}

\subsection{Detecção do DNA do HIV-1 integrado ao ge- noma leucocitário (PCR-DNA quantitativo) ${ }^{(\mathbf{1 5})}$}

Usa-se a reação em cadeia de polimerase-polymerase chain reaction- $P C R$, em especial para o diagnóstico de infecção pelo HIV-1, em crianças nascidas de mães soropositivas, sendo altamente especí- 
fico e sensível em lactentes de um a dois (1-2) meses de idade e para o esclarecimento diagnóstico de indivíduos com perfis indeterminados ao $\mathrm{WB}^{(18)}$.

O teste pode se tornar positivo apenas após trinta (30) a sessenta (60) dias de vida da criança, pois este seria o tempo necessário para que houvesse integração do genoma viral ao genoma leucocitário, em um número significativo de células circulantes. Ainda no primeiro mês de vida da criança, existe a possibilidade de que algumas células infectadas da mãe estejam circulando na criança e representem, portanto, falsa positividade do teste no recém-nascido ${ }^{(18)}$.

$\mathrm{O}$ teste será reagente quando houver presença de células com DNA viral integrado e, portanto, infectadas, e não reagente na ausência de células infectadas pelo HIV-1, dentro do limite de sensibilidade da técnica. A interpretação de testes executados em recém-nascidos requer especial atenção e, freqüentemente, é associada à pesquisa de outros marcadores. A coleta de material para PCR, em papel de filtro, é alternativa útil para estudos de campo, apresentando sensibilidade e especificidade comparáveis às da técnica convencional.

\subsection{Detecção do RNA do HIV-1 no plasma (PCR-RNA qualitativo) ${ }^{(15)}$}

Emprega-se PCR após transcrição reversa (RT-PCR). É indicada para o diagnóstico da infecção pelo HIV-1 em crianças nascidas de mães soropositivas e diagnóstico de infecção pelo HIV-1 em adultos expostos recentemente (até dois (2) ou três (3) meses), portanto antes de soroconversão. Nestes casos, o teste se torna reagente entre quinze (15) a sessenta (60) dias, após a infecção.

A detecção do RNA viral requer cuidados no manuseio e preservação do material clínico. O sangue deve ser colhido adequadamente, as suas células separadas dentro de duas horas e o teste realizado imediatamente ou a amostra estocada a $-70^{\circ} \mathrm{C}$.

Teste reagente significa presença de vírus circulante no plasma e, portanto, infecção, enquanto teste não reagente, ausência de vírus circulante ou presença, em quantidades abaixo do limite, de detecção da técnica.

\subsection{Detecção do RNA do HIV-1 no plasma (quantitativo) ou Determinação da Carga Viral $(\mathbf{C V})^{(19)}$}

A infecção pelo HIV é crônica, persistente, durante a qual o vírus se replica constantemente, sem ser eliminado. No sangue, o vírus pode estar associado às células, sob forma de provírus integrado ao genoma celular, mas aparece, também, sob a forma livre (virion infeccioso), produto da replicação ativa do vírus. A carga viral corresponde à quantidade de vírus replicativo ou latente presente em um indivíduo infectado. Na linguagem corrente, a carga viral do HIV corresponde, geralmente, à quantidade de vírus presente no compartimento sangüíneo. Dependendo da replicação do vírus no sangue, a carga viral pode não ter o mesmo valor: a carga viral celular corresponde à quantidade de provírus que infecta as células mononucleares e reflete o reservatório celular, e a carga viral plasmática corresponde à quantidade de partículas virais, livres no plasma.

A utilização da técnica de PCR permitiu mostrar que o HIV se replica de maneira variável em todos os estágios da doença, o que contradiz a concepção inicial de latência virológica após a primoinfecção.

Esquematicamente, as cargas virais celulares ou plasmáticas podem ser avaliadas por meio de técnicas de culturas celulares ou plasmáticas em diluições sucessivas, que constituem métodos de referência, bem como, por meio de técnicas de biologia molecular (Tabela I).

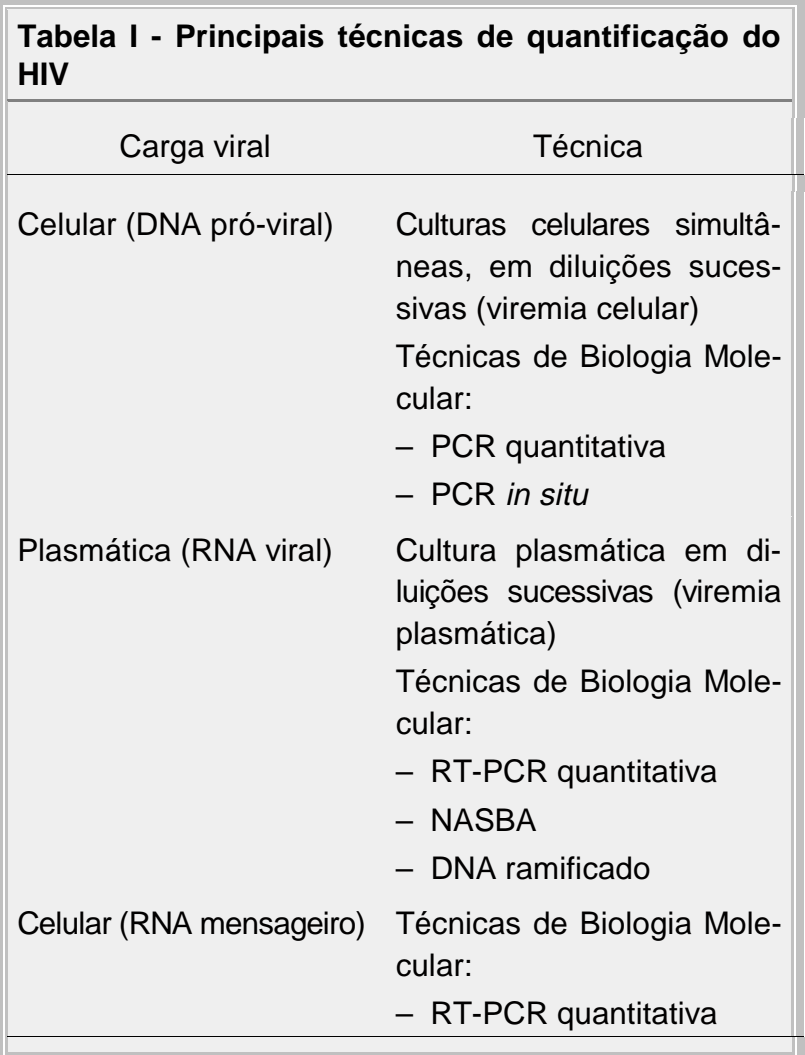


As técnicas mais freqüentemente empregadas para determinação da carga viral são: PCR quantitativo por competição, branched-chain DNA (bDNA), NASBA (Nucleic Acid Sequenced Based Amplification).

A quantificação do RNA viral plasmático pode ser realizada, atualmente, por meio de "kits" comerciais, que utilizam amplificação gênica, tais como a PCR ou NASBA, hibridização molecular, como a técnica do DNA ramificado (Tabela II). Cada um destes "kits" permite obter uma medição da carga viral plasmática extremamente confiável, mas necessita de pessoal qualificado e equipamento específico. A carga viral plasmática é expressa em número de cópias (ou equivalentes-cópias) de RNA viral por ml de plasma, freqüentemente traduzido, para facilitar, num logaritmo de base $10(\log )$.

\begin{tabular}{|c|c|c|c|}
\hline \multicolumn{4}{|c|}{ Tabela II - "Kits" comerciais para avaliação da carga viral plasmática do HIV-1 } \\
\hline & $\begin{array}{l}\text { Quantiplex HIV RNA® } \\
\text { Chiron }\end{array}$ & $\begin{array}{l}\text { Amplicor HIV-1 Monitor }{ }^{\circledR} \\
\text { Roche Diagnostic System }\end{array}$ & $\begin{array}{c}\text { NASBA QR System® } \\
\text { Organon Teknika }\end{array}$ \\
\hline Princípio & Hibridização molecular & $\begin{array}{c}\text { Polimerização por } \\
\text { amplificação em cadeia }\end{array}$ & Amplificação genética \\
\hline Expressão & Eq RNA / ml & cópias / ml & cópias / ml \\
\hline Gene identificado & pol & gag & gag \\
\hline Subtipo M identificado & A a F: sim & $\begin{array}{l}\text { A: - ou } \pm \\
\text { outros subtipos: sim }\end{array}$ & $\begin{array}{l}\text { A: - ou } \pm \\
\text { outros subtipos: sim }\end{array}$ \\
\hline Subtipo $O$ & não & não & não \\
\hline Limite inferior de detecção & 500 & $200-400$ & $\begin{array}{l}400(\text { para } 1 \mathrm{ml}) \\
\text { Nuclisens }=80\end{array}$ \\
\hline Limite superior de detecção & $1,610^{6}$ & $1,510^{6}$ & $110^{7}$ \\
\hline Variação individual & $0,3 \log$ & $0,45 \log$ & $0,3 \log$ \\
\hline Sensibilidade/plasma $\mathrm{HIV}^{+}$ & $70 \%$ & $95 \%$ & $100 \%$ \\
\hline Reprodutividade & +++ & ++ & ++ \\
\hline $\begin{array}{l}\text { - zona cinza de reproduti- } \\
\text { vidade }\end{array}$ & & $<3 \log e>6 \log$ & $<4 \log$ \\
\hline - desvio-padrão intra-ensaio & $0,12-0,2$ & $<0,15-0,33$ & $0,13-0,23$ \\
\hline Anticoagulante & EDTA ou citrato $>$ heparina & EDTA > citrato & EDTA > citrato ou heparina \\
\hline $\begin{array}{l}\text { Tempo de espera para reali- } \\
\text { zação do teste }\end{array}$ & $<6$ horas & $<3$ horas & $<2$ horas \\
\hline Estocagem & $-80^{\circ} \mathrm{C}$ & $-80^{\circ} \mathrm{C}$ & $-80^{\circ} \mathrm{C}$ \\
\hline Volume da amostra & $2 \mathrm{ml}$ & $200 \mu \mathrm{l}$ & $100 \mu \mathrm{l} \mathrm{a} 1 \mathrm{ml}$ \\
\hline Número de testes & 42 / 2 dias & $20 / 1 \mathrm{dia}$ & $10 / 1 \mathrm{dia}$ \\
\hline Rapidez de análise & +++ & ++ & ++ \\
\hline
\end{tabular}


No Brasil, os testes de carga viral estão disponibilizados pelo Ministério da Saúde, em laboratórios de uma rede nacional, em algumas cidades do país, para o acompanhamento de pacientes em uso de terapia anti-retroviral.

Deve-se obedecer às técnicas de coleta, quanto ao volume e presença de EDTA, assim como ser encaminhado o mais rápido possível ao laboratório, a fim de se realizar a separação até, no máximo, três horas após a colheita. O material deve ser processado imediatamente ou estocado a $-70^{\circ} \mathrm{C}$.

Níveis elevados de cópias de RNA viral são associados a mau prognóstico, enquanto níveis baixos guardam relação com curso clínico mais prolongado. Os valores devem ser decrescentes no caso de sucesso da terapêutica antiviral eficaz. Espera-se que o ponto mais baixo da redução da carga viral ocorra nas quatro semanas após o início do tratamento anti-retroviral e, portanto, o primeiro de controle deve ser realizado entre um (1) a três (3) meses após o início do tratamento. Considera-se sucesso virológico a diminuição da carga viral em pelo menos $0,5 \log$ na base 10. Se a carga viral tornar a aumentar, em uso regular da medicação, deve-se considerar a possibilidade da emergência de mutantes resistentes, e considerar a modificação da terapia anti-retroviral.

Hoje em dia, é possível calibrar muito finamente a terapêutica anti-retroviral, por meio da avaliação regular da carga viral plasmática em um paciente tratado.

A seguir são apresentados os "kits" comerciais disponíveis.

Deve-se escolher um único "kit" de avaliação da carga viral plasmática para monitorar um mesmo paciente, embora dados da literatura tenham mostrado correlação dos resultados entre os testes, ficando dentro dos limites de reprodutibilidade do teste, que é inferior a 0,5 log. Existe um interesse do Ministério da Saúde do Brasil em tentar definir um fator de correlação entre os testes mais usados.

\subsection{Quantiplex HIV RNA ${ }^{\circledR}$ (Chiron)}

A técnica do DNA ramificado utiliza uma amplificação do sinal obtido por hibridização molecular sem amplificação gênica. A duração do teste é de dois dias. O limite de detecção do "kit" atualmente comercializado é de 500 Eq-cópias por ml de plasma. A principal vantagem dessa técnica é sua reprodutibilidade. Seu principal defeito é sua baixa sensibilidade.

\subsection{Amplicor HIV-1 - Monitor $^{\circledR}$ (Roche Diag- nostic Systems)}

Este "kit" utiliza a técnica clássica de RT-PCR, em vinte e cinco (25) ciclos, utilizando uma DNA polimerase termoestável, capaz de realizar sucessivamente a transcrição reversa e a amplificação. O número de cópias de cada amostra é calculado com relação ao seu próprio padrão interno. O limite de sensibilidade é de duzentas (200) cópias de RNA por ml de plasma. A duração da reação é de seis (6) horas. Os principais inconvenientes deste "kit" são a incapacidade de reconhecimento de certos subtipos africanos, notadamente do subtipo A, e elevada variação interensaio.

\subsection{NASBA QR System $^{\circledR}$ (Organon Teknika)}

A técnica NASBA permite a amplificação isotérmica do RNA do HIV-1 de filamento simples, utilizando três (3) enzimas: a transcriptase reversa do vírus da mieloblastose aviária, uma RNAse H, e a RNA polimerase do fago T7. A técnica permite a obtenção de $10^{6}$ a $10^{9}$ cópias em menos de uma hora. Seu limite de detecção passou, recentemente, para oitenta (80) cópias do RNA viral por $\mathrm{ml}$ de plasma, recebendo o "kit" o nome de NASBA nuclisens HIV-1 Qt. A variação interensaios do "kit" NASBA é comparável à da PCR Roche.

\subsection{Determinação de Resistência aos Anti-Re- trovirais}

Os testes de determinação de resistência aos anti-retrovirais devem constituir o próximo passo de evolução no monitoramento terapêutico da infecção. Os testes de resistência podem direcionar a terapia no momento da falha. Atualmente, a mudança terapêutica é baseada na clínica, no conhecimento do mecanismo de ação das drogas, carga viral e evolução do TCD4+ e TCD8 ${ }^{+}$. Os testes de resistência podem fazer com que a mudança de terapia seja menos empírica. Além disso, existe o potencial de se predizer a falência biológica antes que ela ocorra. Como exemplo histórico desse refinamento no monitoramento da infecção pelo HIV, pode-se citar os outros marcadores imuno/virológicos. Com o uso do $\mathrm{TCD}^{+}$, por exemplo, pode-se detectar o colapso do sistema imune antes mesmo do aparecimento de um evento clínico de progressão. Com a carga viral, pode-se detectar quais os pacientes que potencialmente estariam evoluindo rapidamente para o colapso do sistema imune, mesmo antes da queda do TCD4 ${ }^{+}$. Talvez com os 
testes de resistência seja possível predizer o momento em que a carga viral pode aumentar, mesmo antes que isso ocorra.

Testes de resistência também serão úteis para melhor introdução de terapia em casos de infecção vertical (mãe-filho), e em acidentes pós-exposição ocupacional, onde a avaliação prévia de cepas resistentes poderá melhor direcionar a terapêutica a ser oferecida ao recém-nascido, ou ao profissional da saúde vítima do acidente com material potencialmente contaminado.

A resistência pode ser medida por ensaios fenotípicos e genotípicos. Os ensaios genotípicos, que identificam, numa seqüência definida de genes, a presença de uma mutação específica, são relativamente rápidos, mas fornecem somente uma medida indireta da resistência. Eles não conseguem detectar espécies minoritárias (ou seja, aquelas que componham menos de $20 \%$ da carga viral) e nem sempre estão correlacionados com o fenótipo. É possível pesquisar as mutações genômicas que conferem resistência a uma substância anti-retroviral por meio de seqüenciamento do gene que codifica o alvo da molécula antiviral, seja após clonagem ou diretamente com produtos de PCR. Quando as mutações que conferem resistência já estão bem identificadas, é possível pesquisá-las por meio de técnicas de Biologia Molecular. A técnica mais utilizada é uma PCR nidificada (isto é, o produto da primeira amplificação serve de alvo a uma segunda amplificação no seu interior). A pesquisa de mutações pontuais que conferem resistência a uma molécula por uma PCR nidificada diferencial, em diluição limitada, é uma técnica relativamente sofisticada, que necessita cerca de três (3) a quatro (4) dias de manipulação.

Os ensaios fenotípicos que medem a capacidade de crescimento in vitro de um organismo isolado na presença de uma droga, representam uma medida mais exata da resistência, mas são mais lentos na sua execução, podem apresentar resultados diferentes em relação à resistência fenotípica real in vivo, e, da mesma forma como ocorre com os ensaios genotípicos, são insensíveis às espécies minoritárias. Considerando-se todos os fatores, a determinação do fenótipo de sensibilidade do HIV aos anti-retrovirais necessita do isolamento do vírus e, posteriormente, sua cultura em muitas diluições, na presença de concentrações crescentes de uma substância anti-retroviral.

É possível que, em futuro próximo, tenhamos disponibilidade de "kits" capazes de mensurar, rotineiramente, o genótipo e o fenótipo de sensibilidade do HIV aos anti-retrovirais.

\subsection{Algumas Considerações sobre Testes Rá- pidos para Diagnóstico da Infecção pelo HIV ${ }^{(20)}$}

Além dos testes sorológicos convencionais, para o diagnóstico da infecção pelo HIV, foram desenvolvidos, mais recentemente, os chamados "testes rápidos", que têm a revelação em cerca de trinta (30) minutos, permitindo análise de sangue, saliva ou urina. Estes testes empregam, geralmente, antígenos virais fixados a um suporte sólido, como membranas de celulose ou nylon, látex, micropartículas, ou cartelas plásticas.

Geralmente, possuem sistema de revelação visual, o que dispensa o uso de equipamento laboratorial, e pode ter implicações práticas para implantação de estudos em regiões sem facilidades laboratoriais.

Atualmente, no mercado, existem diferentes testes de diagnóstico rápido, produzidos por fabricantes distintos, que utilizam diferentes tipos de antígenos, como o lisado viral, proteínas recombinantes, peptídeos sintéticos ou a combinação destes. Geralmente, tem sensibilidade e especificidade inferiores aos ELISAs convencionais. Embora de fácil interpretação, resultados falso-positivos podem ser obtidos, variando de teste a teste, em função de várias razões de ordem técnica.

Resultados falso-negativos também podem ser detectados, principalmente em estudos utilizando amostras de soros provenientes de países onde predominam os subtipos não-B do HIV-1, assim como em amostras de soroconversores recentes.

Por outro lado, o uso de testes rápidos para autotestagem do estado sorológico frente à infecção pelo HIV por casais antes do início da prática sexual pode levar ao abandono da utilização de preservativos como meio de prevenção, podendo servir como uma arma para a discriminação dos indivíduos em relacionamentos, emprego ou outras situações.

A Comissão Nacional de aids traçou uma série de recomendações para o emprego desses testes, entre elas evitar a vulgarização do emprego para o diagnóstico da infecção pelo HIV e não ser usado por profissional não credenciado. O seu emprego poderia ser realizado, em casos de acidentes ocupacionais com material potencialmente contaminado, pelo profissional da saúde, em estudos epidemiológicos ou em triagens de bancos de sangue.

Agradecimentos: Os autores agradecem à bióloga Rita Angela S. Cardoso pela cessão das fitas do teste Western Blot. 
MACHADO AA \& COSTA JC. Laboratory methods for the diagnosis of human immunodeficiency virus (HIV) infection. Medicina, Ribeirão Preto, 32: 138-146, apr./june 1999.

ABSTRACT: The authors review the laboratory methods available for the diagnosis of the Human Imunodeficiency Virus (HIV) infection with emphasis on thes correct application and interpretation of the results.

UNITERMS: HIV. Acquired Immunodeficiency Syndrome. Diagnosis, Laboratory. Enzyme-Linked Immunosorbent Assay. Blotting, Western.

\section{REFERÊNCIAS BIBLIOGRÁFICAS}

1 - GOTTLIEB MS et al. Pneumocystis carinii pneumonia and mucosal candidiasis in previously healthy homosexual men: evidence of a new acquired cellular immunodeficiency. $\mathbf{N}$ Engl J Med 305: 1425-1431, 1981.

2 - MASUR H et al. An outbreak of community - acquired Pneumocystis carinii pneumonia initialmanifestation of cellular immune dysfunction. N Engl J Med 305: 1431-1438, 1981.

3 - BARRÉ-SINOUSSI F et al. Isolation of a T-lymphotropic retrovirus from a patient at risk for acquired immune deficiency syndrome (AIDS). Science 220: 868-871, 1983.

4 - POPOVIC M et al. Detection, isolation, and continuous production of cytopathic retrovirus (HTLV-III) from patients with AIDS and pre-AIDS. Science 224: 497-500, 1984.

5 - LEVINSON SS \& DENYS GA. Strengths and weaknesses in methods for identifying the causative agent(s) of acquired immunodeficiency syndrome (AIDS). CRC Crit Rev Clin Lab Sci 26: 277-302, 1988.

6 - HOUN HY; PAPPAS AA \& WALKER JR EM. Status of current clinical tests for human immunodeficiency virus (HIV): applications and limitations. Ann Clin Lab Sci 17: 279-283, 1987.

7 - LEVY JA. Pathogenesis of Human Immunodeficiency Virus infection. Microbiol Rev 57 : 183-289, 1983.

8 - NOWAK MA \& MCMICHAEL AJ. How HIV defeats the immune system. Sci Am 273 : 42-49,1995.

9 - PANTALEO G et al. Immunopathogenesis of Human Immunodeficiency Virus infection. In: DE VITTA JR VT; HELLMAN $S$ \& ROSENBERG SA, eds. AIDS etiology, diagnosis, treatment and prevention, 4th ed, J. B. Lippincott, Philadelphia, cap. 4, p. 75-88, 1997.

10 - HENDRY RM et al. Lack of evidence for HIV-2 infection among at-risk individual in Brazil. J AIDS 4: 623-627,1991.

11 - PIENIAZEK D et al. Identification of mixed HIV-1/HIV-2 infections in Brazil by polymerase chain reaction. AIDS $\mathbf{5}$ : 1293-1299, 1991.
12 - MACHADO AA et al. Ocorrência de falso positivo em testes com peptídeos sintéticos para pesquisa de anticorpos contra HIV-2 em pacientes brasileiros com HIV-1. Rev Soc Bras Med Trop, 29 : 615-617, 1996.

13 - KELLER GH \& MANAK MM. Detection of HIV-1 nucleic acid in clinical samples using target DNA amplification and nonisotopic probes. In: KHAN NC \& MILNICK JL, eds. Human Immunodeficiency Virus: innovative techniques. Karger, Basel, p. 28-60, 1990. (Monographs in Virology, 18)

14 - METCALF JA; DAVEY JR RT \& LANE HC. Acquired immunodeficiency syndrome serologic and virologic tests. In : DE VITTA JR VT; HELLMAN S \& ROSENBERG SA, eds. AIDS etiology, diagnosis, treatment and prevention, 4th ed, J. B. Lippincott, Philadelphia, cap. 11, p. 177-195, 1997.

15 - GRANATO CFH. Uso clínico dos marcadores laboratoriais ligados à infecção pelo vírus da imunodeficiência adquirida do tipo 1 (HIV-1). J SBI 4: 4, 1996.

16 - WOOD HC \& WREGHITT TG. Techiniques. In: WREGHITT TG \& MORGAN-CAPNER P, eds. Elisa in the clinical microbiology laboratory, Public Health Laboratory Service, London, cap 1, p. 6-21, 1990.

17 - CENTERS FOR DISEASE CONTROL. Interpretation and use of the Western blot assay for serodiagnosis of human immunodeficiency virus type 1 infections. MMWR 38: 1-7, 1989.

18 - OWENS DK et al. A metanalytic evaluation of the polymerase chain reaction for the diagnosis of HIV infection in infants. JAMA 275: 1342-1348, 1996.

19 - BELEC L. Carga viral circulante no decorrer da infecção pelo HIV-1; métodos de avaliação, aplicações clínicas e terapêuticas. In: Anais, Seminário de Cooperação BrasilFrança. Os ensaios clínicos dentro do quadro da infecção pelo HIV/aids, Salvador, BA, 23 a 25 de outubro de 1996. Ministério da Saúde, Secretaria de Políticas de Saúde Coordenação Nacional de DST e AIDS, p. 83-108, 1998.

20 - MORGADO MG. Testes rápidos para o diagnóstico da infecção pleo HIV: considerações técnicas e éticas para seu uso. AIDS. Bol Epidemiol ano X: semana 36 a 48 , 1997.

Recebido para publicação em 05/05/99

Aprovado para publicação em 02/06/99 